\title{
Stent-Assisted Coiling Using Leo+ Baby Stent
}

\author{
Immediate and Mid-Term Results
}

\author{
Hannes Luecking ${ }^{1} \cdot$ Tobias Struffert $^{1,4} \cdot$ Philipp Goelitz $^{1} \cdot$ Tobias Engelhorn $^{1} \cdot$ Sebastian Brandner ${ }^{2}$ \\ Joji B. Kuramatsu ${ }^{3}$ Stefan Lang ${ }^{1}$. Manuel Schmidt ${ }^{1}$. Arnd Doerfler ${ }^{1}$
}

Received: 1 October 2019/ Accepted: 1 April 2020 / Published online: 8 May 2020

(c) The Author(s) 2020

\begin{abstract}
Background Stent-assisted coiling is well-established for treatment of cerebral aneurysms. The technique enables treatment of wide-neck, bifurcation and recurrent aneurysms with high packing rates. While described in extenso for laser cut stents, the results of patients treated with the Leo+ Baby (Balt, Montmorency, France) braided microstent are presented.

Material and Methods Patients were included if treated with a Leo+ Baby and with digital subtraction angiography (DSA) follow-up available of at least 6 months. Data were evaluated for successful deployment, aneurysm occlusion according to the modified Raymond-Roy classification (MRRC), stent patency and procedure-related morbidity and mortality.

Results A total of 81 patients were included and Leo+ Baby deployment was successful in all cases. Coils were used in 80 cases. In 1 case 2 stents were used stent-in-stent without additional coiling. Initial aneurysm occlusion rates were $\mathrm{MRRC}_{\mathrm{i}} 151.9 \%, \mathrm{MRRC}_{\mathrm{i}} 211.1 \%, \mathrm{MRRC}_{\mathrm{i}} 3 \mathrm{a} 24.7 \%$ and $\mathrm{MRRC}_{\mathrm{i}} 3 \mathrm{~b} 12.3 \%$. Occlusion rates after 6 months were $\mathrm{MRRC}_{6 \mathrm{~m}} 1$ $78.9 \%, \mathrm{MRRC}_{6 \mathrm{~m}} 23.9 \%, \mathrm{MRRC}_{6 \mathrm{~m}} 3 \mathrm{a} 6.6 \%$ and $\mathrm{MRRC}_{6 \mathrm{~m}} 3 \mathrm{~b} 10.5 \%$. Procedure-related morbidity was 1 case of acute stent thrombosis successfully treated with tirofiban and 1 case with transient hemiparesis due to stent thrombosis after 4 months. There was 1 case of coil-associated subarachnoid hemorrhage (SAH) which caused prolonged hospitalization. No procedure-related mortality was observed.

Conclusion The results confirm that stent-assisted coiling with the Leo+ Baby stent is safe and efficient for treatment of wide neck or recurrent cerebral aneurysms. Spontaneous progressive aneurysm occlusion over 6 months supports the theory of considerable flow-modulating effects of Leo+ Baby.
\end{abstract}

Keywords Low profile stent · Braided stent - Cerebral aneurysm · Coiling $\cdot$ Bifurcation aneurysm

\section{Introduction}

T. Struffert and H. Luecking contributed equally to this publication.

Hannes Luecking

hannes.luecking@uk-erlangen.de

1 Department of Neuroradiology, University of Erlangen-Nuremberg, Schwabachanlage 6, 91054 Erlangen, Germany

2 Department of Neurosurgery, University of Erlangen-Nuremberg, Erlangen, Germany

3 Department of Neurology, University of Erlangen-Nuremberg, Erlangen, Germany

4 Department of Neuroradiology, University of Giessen, Giessen, Germany
In the last decade the possibilities for endovascular treatment of cerebral aneurysms (CA) have been considerably extended and studies have proved lower morbidity and mortality for coiling than for surgical clipping [1, 2]; however, many aneurysms are still challenging to treat, especially if very small, wide neck, located at a bifurcation or at distant parent vessels [3].

If plain or balloon-assisted coiling is not feasible, the additional use of new generation braided microstents (BMS) may represent an option for those aneurysms [4]. The braided (thus kind of closed cell) design helps to prevent coil dislocation and is assumed to provide a blood flowmodulating effect like a flow-diverting stent (FDS) device $[5,6]$. Free to move strut intersections are responsible for good compliance of these stents, which can facilitate adap- 

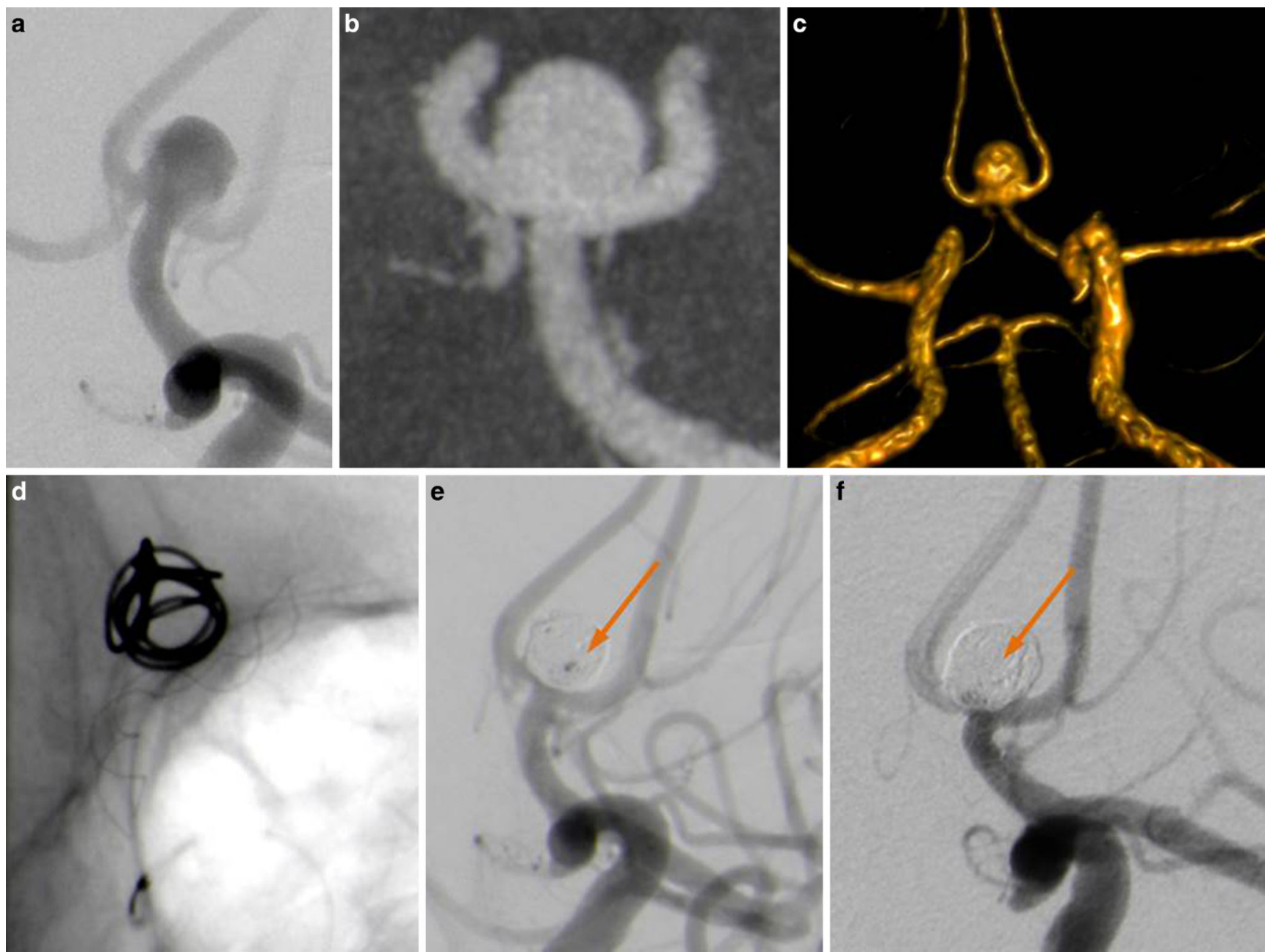

Fig. 1 Wide-neck Acom aneurysm involving both A2 branches (a, b). FD-CT with iv contrast (c) shows dominant feeding of both A2 branches from the left side. Note the two helical marker strands (d) indicating complete opening of the stent. Arrow in e marks residual central inflow (MRRC3a) by the end of the procedure which had disappeared at follow-up (f). a, b and $\mathbf{d}-\mathbf{f}$ show DSA images

tation to complex vessel anatomies. Currently used devices, such as the Leo+ Baby (Balt, Montmorency, France) or the Lvis jr. (MicroVention, Tustin, CA, USA) are equipped with two radiopaque strands arranged as a double helix to assess stent opening under fluoroscopy (Fig. 1d).

Beside the jailing technique the higher porosity of BMS compared to FDS enables a microcatheter to be advanced through the mesh after deployment. The low stent profile enables usage of $0.017 \mathrm{in}$. microcatheters (MC) for stent delivery, which facilitates access to small and distal vessels. Depending on the stent diameter BMS deployment is possible in parent vessel sizes down to $1.5 \mathrm{~mm}$ in diameter. As with laser-cut stents complex constructs like T-stenting or kissing stents are attainable $[7,8]$ as well. Due to the braided design it is possible to re-capture a BMS if already deployed up to $80 \%$ of the total stent lenght. This enables precise positioning or if necessary, complete removal and exchange of the device.

Data on the use of these devices are still rarely documented in literature. This study reports on a single center experience and mid-term results in a series of 81 aneurysms treated by a BMS (Leo+ Baby) stent-assisted coiling.

\section{Material and Methods}

We reviewed our data base retrospectively and included all patients treated by a Leo+ Baby stent since April 2014 . Patients were included if a follow-up angiogram within at least 6 months was available. 


\section{Medication and Preparation}

Based on our institutional standards patients were prepared with $75 \mathrm{mg}$ of clopidogrel and $100 \mathrm{mg}$ of aspirin (ASA) 7 days prior to treatment procedure. Upon deployment 5000 IU of heparin was administered. All procedures were performed with the patient under general anesthesia. There was 1 case with acute subarachnoid hemorrhage (SAH) who was administered $250 \mathrm{mg}$ of ASA and $5000 \mathrm{IU}$ of heparin prior to stent deployment and $300 \mathrm{mg}$ of clopidogrel via a gastric tube with a $2 \mathrm{~h}$ interval.

Depending on follow-up clopidogrel was stopped routinely after 6 weeks whereas aspirin was continued until at least 1.5 years posttreatment.

In our institution platelet function testing (Multiplate ${ }^{\circledR}$ Analyzer Array (Roche Deutschland Holding GmbH; Grenzach-Wyhlen, Germany) is available from the central laboratory) is not performed routinely for patients scheduled for stenting, as opposed to patients planned for flow-diverters.

\section{Treatment Procedure}

Prior to treatment all patients underwent diagnostic catheter angiography for treatment planning including 3-D rotational angiography. All treatments were performed on a biplane flat detector angiographic system (Artis zee Biplane System, Siemens AG, Healthineers, Forchheim, Germany). After the treatment procedure flat-detector computed tomography (FD-CT) is routinely acquired to rule out procedurerelated hemorrhage.

Leo+ Baby stent is delivered via a $0.017^{\prime \prime}$ microcatheter (MC). Usage of a Vasco $+10 \mathrm{MC}$ (Balt) is recommended by the manufacturer, although use of any MC of the same inner diameter is possible. Vasco +10 is relatively stiff to facilitate re-capturing the stent, which-on the other hand-sometimes causes difficulties to probe tortuous vessels or sharp angels. In those cases an Echelon $10 \mathrm{MC}$ (Medtronic, Irvine, CA, USA) was used.

Bioactive Cerecyte ${ }^{\mathrm{TM}}$ coils (Codman Neuro; Raynham, MA, USA) were used according to the aneurysm size. Coil packing as dense as possible was always attempted. If applicable, the MC was jailed within the aneurysm lumen prior to deployment $(n=72)$ or after deployment through the stent struts $(n=8)$.

\section{Imaging Follow-up}

As a standard procedure magnetic resonance imaging (MRI), diffusion and perfusion weighted imaging (DWI/ PWI), time-of-flight and contrast-enhanced angiography, T2w FLAIR (fluid attenuated inversion recovery), T2* and contrast enhanced $\mathrm{T} 1 \mathrm{w}$ sequences and contrast-enhanced FD-CT (source images, multiplane and volume rendering technique (VRT) reconstructions) [9, 10] were acquired 2 weeks and 3 months after intervention to monitor brain parenchyma (e.g. silent ischemia), BMS configuration and BMS lumen. As the current gold standard DSA was performed at 6 months after treatment.

\section{Imaging Evaluation}

Follow-up imaging was evaluated by two experienced interventionists in consensus reading.

The modified Raymond-Roy classification (MRRC) [11] was used for occlusion assessment in DSA, FD-CT and MRA $($ MRRC $1=$ complete occlusion; MRRC $2=$ neck remnant (dog ear); MRRC3a = residual aneurysm, without contact to aneurysm wall; MRRC $3 \mathrm{~b}=$ residual aneurysm, with contact to aneurysm wall).

Wall adaptation, BMS configuration, endothelial hyperplasia and in-stent-thrombosis were evaluated in DSA and FD-CT. Cut-off for report of endothelial hyperplasia was $20 \%$ of the stent lumen. MRI was evaluated for indirect signs of BMS malfunction (e.g. by time-to-peak delay in PWI).

MRI was also analyzed for asymptomatic pathologic changes of brain tissue (e.g. post-ischemic lesions, inflammation, etc.) and hemorrhage.

\section{Clinical Follow-up}

Patients were examined by a neurologist or neurosurgeon at admission, after the procedure, and at discharge. Assessment criteria were procedure-related neurologic deficits or death. Furthermore, all patients were clinically assessed at the follow-up visits.

\section{Results}

All data were analyzed and interpreted by two experienced (11 and 20 years) interventionists.

\section{Patient Inclusion}

A total of 81 consecutive patients treated with a Leo+ Baby stent were identified.

Of the patients 5 refused to have DSA follow-up and underwent follow-up with FD-CT and MRI. In these 5 cases the aneurysm was rated as MRRC1 (complete occlusion) after 6 months.

Mean dome-to-neck ratio was $1.06 \pm 0.22$, indicating that only wide neck aneurysms had been selected to justify stentassisted coiling. 
Table 1 Demographic data and aneurysm anatomy of all patients initially included

$\begin{array}{llll}\text { Demography } & \text { Overall } & \text { Female } & \text { Male } \\ \text { Sex } & 81 & 55 & 26 \\ \text { Age (years) } & 58.1 \pm 11.9(16-85) & 57.9 \pm 10.2(16-85) & 58.7 \pm 12.7(35-77) \\ \text { Aneurysm anatomy } & & & \\ \text { Aneurysm size (mm) } & 4.6 \pm 2.4(2.0-12.5) & \\ \text { Dome/neck ratio } & 1.06 \pm 0.22 & \text { ACA: 43; MCA: 18; PCA/BA: 14; PCA: 5; PICA: } 1 & \\ \text { Location } & \end{array}$

$A C A / M C A / P C A$ anterior/middle/posterior cerebral artery, BA basilar artery, PICA posterior inferior cerebellar artery

\section{Technical Procedure}

Deployment of the BMS ( $n=86)$ was successful in all cases, although in 3 cases the stent chosen was too short and a second stent had to be attached at the proximal end. In 2 cases 2 BMSs were used for T-stenting. In 1 case of a fusiform aneurysm 2 BMS were used stent-in-stent to achieve a flow-diverting effect $\left(\mathrm{MRRC}_{\mathrm{i}}=3 \mathrm{~b} ; \mathrm{MRRC}_{6 \mathrm{M}}=1\right)$. In 8 cases the aneurysm was coiled through the stent mesh whereas in 72 cases the MC was jailed.

In 3 cases the stent-carrying $\mathrm{MC}$ needed to be looped through the aneurysm to probe the distal orifice of the parent vessel and a stent-retriever was used to straighten the MC. These interventions were otherwise unremarkable. In 1 case the jailed MC popped out of the aneurysm during stent deployment (aneurysm mean size $2.7 \mathrm{~mm}$ ) so that coiling was done in a second intervention 6 weeks later after the stent was assumed to be integrated into the vessel wall.

Table 1 provides an overview of demographic data and aneurysm anatomy.

\section{Procedural Safety}

We observed 1 patient with acute in-stent thrombosis during the procedure. The thrombosis was successfully treated by tirofiban infusion (a simplified scheme for a package size of $250 \mathrm{ml} / 50 \mu \mathrm{g} / \mathrm{ml}$ is used with an initial dose of $25 \mathrm{ml}$ at a flow rate of $50 \mathrm{ml} / \mathrm{h}$, with the remaining $225 \mathrm{ml}$ being administered at a flow rate of $9 \mathrm{ml} / \mathrm{h}$ for approximately 23 hours). Postprocedural MRI with DWI showed no diffusion restriction in this case. There were no further acute complications requiring particular treatment. By the end of the procedure all stents were patent. Good wall adaptation at the proximal and distal landing zones was documented in all cases at least in 2D DSA or, if not impaired by hardening artifacts, also in 3D imaging. Postprocedural MRI $(n=78$, 2 cases with cardiac pacemaker, 1 not done due to clinical conditions after SAH) was unremarkable in 64 cases, 11 patients had 1-3 punctual DWI lesions, 3 patients had $>3$ DWI lesions. No territorial infarct was recorded. All patients were non-symptomatic for the DWI lesions.
There was 1 case of new hemorrhage in postprocedural non-enhanced FD-CT with fluoroscopy documented coil perforation, which was judged as not directly associated with the Leo+ Baby. The patient completely recovered. Yet, this led to prolonged hospitalization.

There was no procedure-associated mortality.

\section{Initial Occlusion Rate}

In the 81 patients initially treated $\mathrm{MRRC}_{\mathrm{i}} 1$ was assessed in 35 cases $(51.9 \%)$ by the end of the procedure. $\mathrm{MRRC}_{\mathrm{i}} 2$ was found in 5 cases $(11.1 \%), \mathrm{MRRC}_{\mathrm{i}} 3 \mathrm{a}$ in 16 cases $(24.7 \%)$ and $\mathrm{MRRC}_{\mathrm{i}} 3 \mathrm{~b}$ in 6 cases $(12.3 \%)$.

Table 2 summarizes the procedure and follow-up results.

\section{Follow-up}

DSA follow-up was available in 76 patients. Mean time interval to the procedure was 7.2 \pm 1.6 months (range 5-11 months). After 6 months complete aneurysm occlusion $\mathrm{MRRC}_{6 \mathrm{M}} 1$ was assessed in 60 cases $(78.9 \%)$ whereas $\mathrm{MRRC}_{6 \mathrm{M}} 2$ was found in 2 cases $(3.9 \%), \mathrm{MRRC}_{6 \mathrm{M}} 3 \mathrm{a}$ in 5 cases $(6.6 \%)$ and $\mathrm{MRRC}_{6 \mathrm{M}} 3 \mathrm{~b}$ in 8 cases $(10.5 \%)$. The 5 missing patients refused to have DSA for follow-up; however, they underwent non-invasive follow-up with MRI and contrast-enhanced FD-CT which showed complete occlusion in all 5 patients.

DSA showed no stent migration or other changes in device configuration. All stents were patent except for 1 case. A 16-year-old girl was admitted to a hospital nearby 4 months after treatment of a proximal posterior cerebral artery (PCA) aneurysm for severe headaches and a mild sensorimotor hemiparesis. MRI there showed a complete occlusion of the stent and aneurysm. The P1 segment was occluded and an infarct $5 \mathrm{~mm}$ in size of the left (ipsilateral) thalamus was present. Stent thrombosis was confirmed by DSA. The symptoms dissolved until discharge. When the patient was admitted to our department for routine followup after 6 months she had almost completely recovered.

Endothelial hyperplasia was found in 2 cases within the first 3 months without hemodynamic effect in PWI. Yet, 
Table 2 Occlusion rates and adverse events during procedure and after 6 months of follow-up

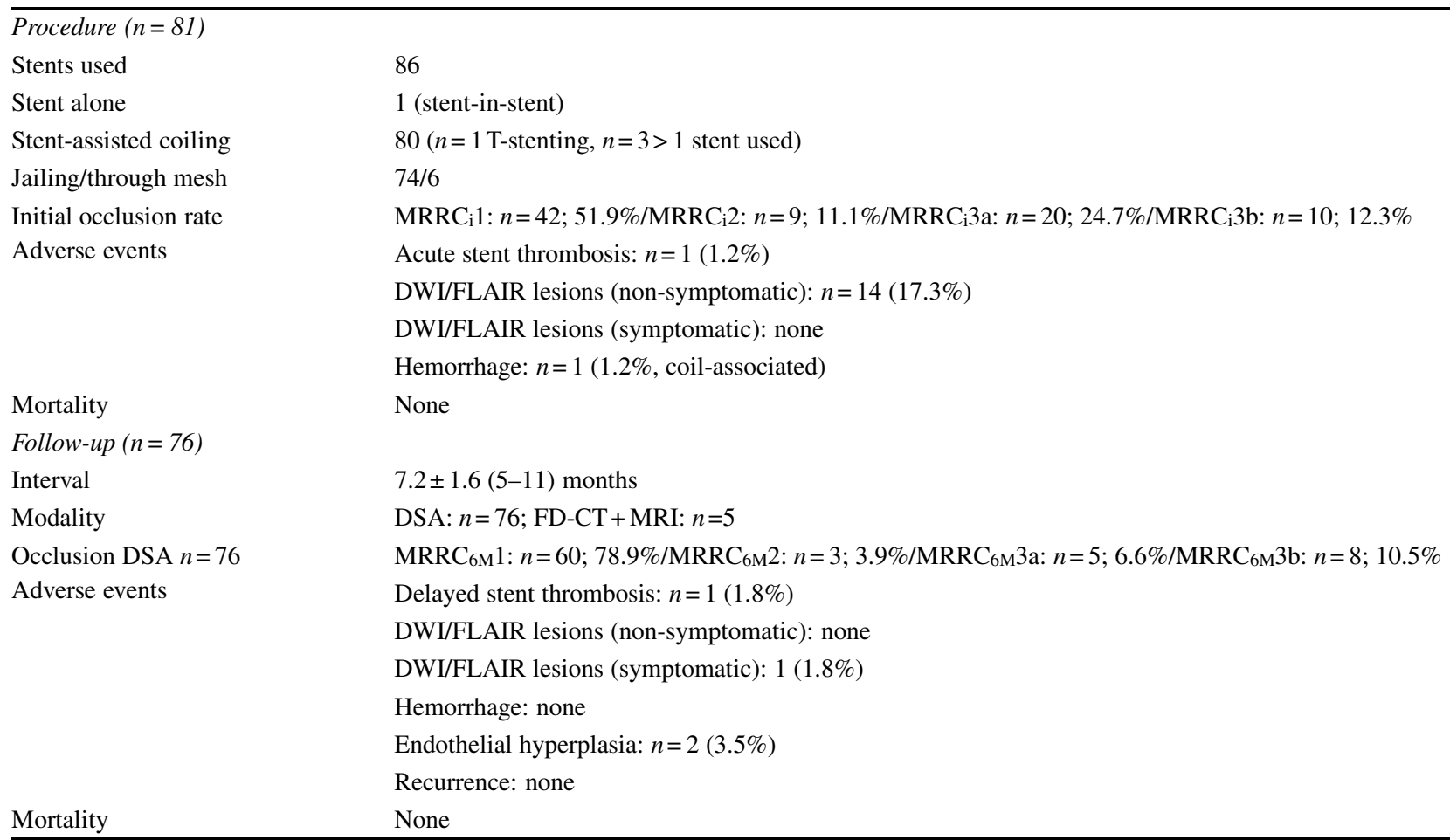

dual platelet inhibition had been extended until the angiography for those cases.

MRI after 6 months was available in all patients $(n=79)$ except in two cases (cardiac pacemaker). Except for the 16-year-old patient already mentioned there were no new DWI or FLAIR lesions nor was there any further case of hemorrhage.

Spontaneous subarachnoid hemorrhage or mortality was not observed during follow-up.

Table 1 provides an overview over demographic data and aneurysm anatomy. Table 2 summarizes the procedure and follow-up results. For a graphic presentation of initial and 6 months occlusion rates see Fig. 2.

\section{Discussion}

Treatment of wide-neck or recurrent cerebral aneurysms can still be challenging if located at the periphery or if a bifurcation is involved. Balloon-assisted coiling is an option in certain situations but bears a higher risk of retreatment $[12,13]$. In addition to laser-cut stents, flow-diverters and bifurcation devices (stent-like or intrasaccular) a number of low-profile braided stents are available designed to treat peripheral or otherwise difficult to treat aneurysms. We report on our experience with the Leo+ Baby braided stent in a series of 81 patients.

\section{Procedure}

Leo+ Baby deployment and aneurysm coverage was finally successful in all cases, although in 3 cases a second stent was necessary to completely cover the aneurysm.

Due to their particular construction with free to move strut intersections Leo+ stents are able to open considerably (up to $0.6 \mathrm{~mm}$ ) wider than their nominal diameter while their length decreases substantially if the chosen stent is too small in relation to the parent vessel diameter. This property may help to more reliably achieve complete wall adaptation as unintended minor undersizing can be compensated. Also, this property may allow a better reconstruction of the aneurysm neck as deliberate bulging of the stent, e.g. at wide bifurcations, can be achieved.

For planning we recommend consulting all modalities available, i.e. $2 \mathrm{D}$ and $3 \mathrm{D}$ data from DSA to determine a BMS size equal to or slightly smaller than the maximum parent vessel diameter. If the length measurement, which can most accurately be done be micro-wire, is between two sizes, it is our experience to rather choose a longer than a shorter size.

There was only one case of acute stent thrombosis which could be treated successfully by tirofiban intra-arterial injection without clinical sequelae. In our center patients to be treated with a BMS are not tested for drug response. It is our experience that thromboembolic complications are 

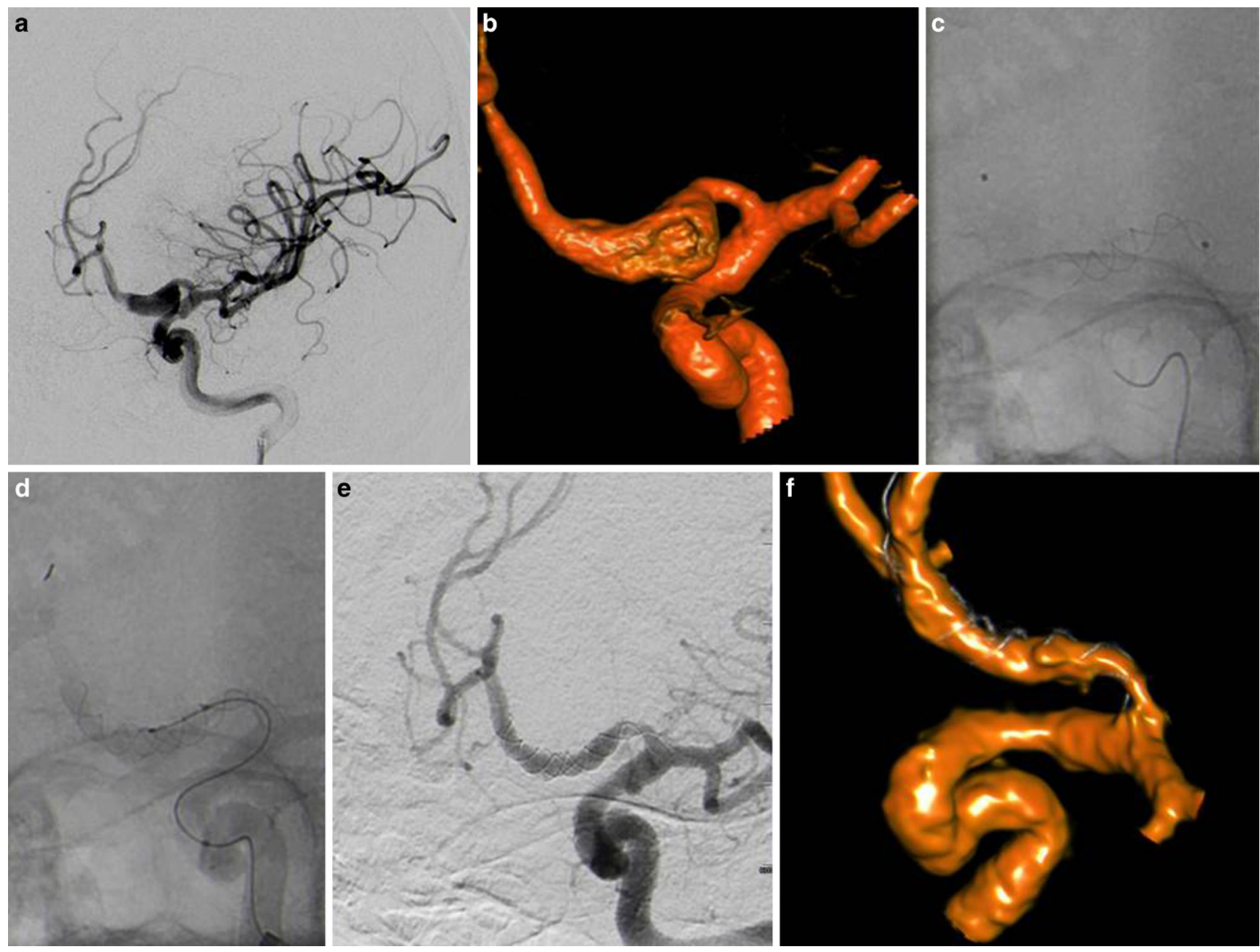

Fig. 2 Incidental dissecting aneurysm of the left A1-segment in DSA and FD-CT with intraarterial contrast application (a, b). Placement of two overlapping Leo+ Baby (Balt, Montmorency; $2.5 \times 25$ and $2.5 \times 18 \mathrm{~mm}$; c, d). Follow-up after 5.6 months shows complete occlusion in DSA and FD-CT with intraarterial contrast application (f). FD-CT is of limited quality due to movement artifacts

rare with these devices and there is even hint for no more complications in drug non-responders [14].

No territorial infarcts were observed. A total of $14 / 78 \mathrm{pa}-$ tients $(17.9 \%)$ showed punctual DWI lesions in postinterventional MRI.

There was 1 case of procedure-related hemorrhage. This was verifiably caused by coil perforation and thus was assessed to be not associated with the stent itself. Yet, procedure-related hemorrhage in general can take a more unfavorable course in patients prepared with dual anti-platelet therapy. Furthermore, the risk of coil perforation in smaller aneurysms can be increased when using the jailing technique as a higher force can be applied with the $\mathrm{MC}$ retained between the stent and the vessel wall.

\section{Aneurysm Occlusion}

Occlusion rates by the end of intervention were $60.5 \%$ $M_{R R C} 1$ and 2, 26.3\% MRRC $\mathrm{C}_{\mathrm{i}} 3 \mathrm{a}$ and $13.2 \% \mathrm{MRRC}_{\mathrm{i}} 3 \mathrm{~b}$. We noticed a shift in sufficient occlusion after 6 months to $82.8 \%\left(\mathrm{MRRC}_{6 \mathrm{M}} 1: n=60\right.$ (78.9\%); $\mathrm{MRRC}_{6 \mathrm{M}} 2: n=2$ (3.9\%)). The rate of MRRC $_{6 \mathrm{M}} 3 \mathrm{a}$ and $3 \mathrm{~b}$ decreased to 6.6 and $10.5 \%$, respectively. In our study population none of

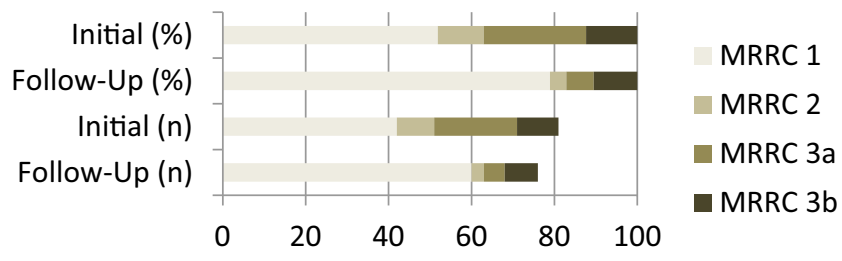

Fig. 3 Shift of occlusion rates (absolute numbers) from treatment to 6 months follow-up 
the MRRC3a/b patients was scheduled for retreatment so far as all patients were at least still on aspirin and potential further spontaneous occlusion should be awaited.

The shift from relatively low initial occlusion rates to high rates of $>80 \%$ within several months otherwise is a typical feature and designated working principle of lowporosity flow diverter stents [15-18]. Although in our study group all patients were still at least on aspirin, we observed spontaneous complete occlusion from $\mathrm{MRRC}_{\mathrm{i}} 2 / 3 \mathrm{a} / 3 \mathrm{~b}$ to MRRC $_{6 \mathrm{M}} 1$ in as many as $23.6 \%(n=18)$ of patients. This included 1 case in which 2 overlapping Leo+ Baby were used without coiling for treatment of a fusiform $11 \times 7 \mathrm{~mm}$ aneurysm (Fig. 3). An explanation is the higher metal coverage (smaller cell size) of the Leo+ Baby compared to other laser-cut and braided MSs-although it is still not comparable to typical FDSs [3, 19]. A smaller cell size works as a more effective scaffold for endothelial growth leading to a progressive sealing of the aneurysm neck [20, 21]. This can result in short-term to mid-term aneurysm occlusion. Also, it is possible to condense the stent struts at the aneurysm neck with braided devices, which helps to further increase metal coverage. A flow-diverting effect of BMS had already been discussed by Machi et al. [22] and Pumar et al. [23]. Neointimal thickness, on the other hand, is reported to be positively correlated with metal coverage [21]. This should be kept in mind in treatment of very small parent vessels.

A positive side effect of the lower porosity is an assumed lower risk of losing coils in treatment of very small aneurysms.

Djurdjevic et al. [24] recently reported on a series of 101 patients treated with Leo+ Baby. In their follow-up after 3-6 months they found complete aneurysm occlusion in $37.9 \%$, residual neck in $25.3 \%$ and residual aneurysm in $36.8 \%$. Although progressive occlusion occurred in $21.8 \%$ these occlusion rates are remarkably lower compared to our results. A relatively low rate of initial MRRC1 occlusion in their group of $24.7 \%$ and a rate of $15 \%$ and $17.2 \%$ of MRRC3a and MRRC3b, respectively, led us to the assumption that a somewhat loose coil packing might have been the cause for these results. Machi et al. reported on a series of 29 patients with initial occlusion rates of $55 \%, 27 \%$ and $10 \%$ (MRRC1, 2 and $3 a+3 b$, respectively), with follow-up occlusion rates of as much as $96 \%$ MRRC1 and $4 \%$ MRRC2. Aydin et al. [25] observed complete aneurysm occlusion after 7 months in $85.7 \%$ in 80 patients after initial complete occlusion of $75 \%$.

\section{Delayed Complications}

During the follow-up there was delayed stent thrombosis in 1 case although 3 months MRI and FD-CT was nonremarkable. In MRI a circumscribed $5 \mathrm{~mm}$ infarct of the left thalamus was found. Anamnesis yielded a continuous taking of ASS and clopidogrel. As this patient had almost co-dominant P1 and posterior communicating segments we assume that minor hemodynamic changes caused by the BMS placed in the P1 segment may have caused the stent thrombosis. The patient recovered from the mild sensorimotor hemiparesis until the regular follow-up after 6 months. We recorded no further ischemic events. Djurdjevic et al. found delayed ischemic complication in 4 patients $(4 \%)$ although dual platelet inhibition was administered for at least 6 months with aspirin monotherapy thereafter for at least another 6 months. Yet, in two cases the patient's drug compliance was reported to be uncertain.

Neither stent-associated hemorrhage nor mortality was recorded during the procedure or in the follow-up period. In the meta-analysis by Cagnazzo et al. an overall mortality of $1.1 \%$ out of 750 aneurysms treated with different kinds of microstents was reported.

\section{Limitations}

The major limitation of this survey is the retrospective single-center design and constricted time interval. A long-term follow-up will be complemented as soon as the data will be available with special respect to stable occlusion and possible progressive occlusion.

\section{Conclusion}

Our results confirm that stent-assisted coiling of complex and recurrent cerebral aneurysms using Leo+ Baby braided microstent goes along with high procedural safety and high rates of aneurysm occlusion after 6 months. We observed a high percentage of progressive occlusion and no case of recurrence, suggesting a relevant flow-modulating effect of this particular stent.

Funding Open Access funding provided by Projekt DEAL.

Conflict of interest H. Luecking, T. Struffert, P. Goelitz, T. Engelhorn, S. Brandner, J.B. Kuramatsu, S. Lang, M. Schmidt and A. Doerfler declare that they have no competing interests.

Open Access This article is licensed under a Creative Commons Attribution 4.0 International License, which permits use, sharing, adaptation, distribution and reproduction in any medium or format, as long as you give appropriate credit to the original author(s) and the source, provide a link to the Creative Commons licence, and indicate if changes were made. The images or other third party material in this article are included in the article's Creative Commons licence, unless indicated otherwise in a credit line to the material. If material is not included in the article's Creative Commons licence and your intended use is not permitted by statutory regulation or exceeds the permitted use, you will need to obtain permission directly from the copyright holder. To view a copy of this licence, visit http://creativecommons.org/licenses/by/4. $0 /$. 


\section{References}

1. Molyneux A, Kerr R, Stratton I, Sandercock P, Clarke M, Shrimpton J, Holman R. International Subarachnoid Aneurysm Trial (ISAT) of neurosurgical clipping versus endovascular coiling 2143 patients with ruptured intracranial aneurysms: a randomised trial. Lancet. 2002;360:1267-74.

2. Lindgren A, Vergouwen MD, van der Schaaf I, Algra A, Wermer M, Clarke MJ, Rinkel GJ. Endovascular coiling versus neurosurgical clipping for people with aneurysmal subarachnoid haemorrhage. Cochrane Database Syst Rev. 2018;8:CD003085.

3. Negrotto M, Crosa R, Casagrande W. Assisted coiling using LEO Baby or LVIS Jr stents: Report of six cases. Interv Neuroradiol. 2015;21:566-74.

4. Voigt P, Schob S, Jantschke R, Nestler U, Krause M, Weise D, Lobsien D, Hoffmann KT, Quäschling U. Stent-assisted coiling of ruptured and incidental aneurysms of the Intracranial circulation using moderately flow-redirecting, braided Leo stents-initial experience in 39 patients. Front Neurol. 2017;8:602.

5. Dall'olio M, Calbucci F, Fioravanti A, Bortolotti C, Cirillo L, Princiotta C, Leonardi M. Revascularized giant aneurysm of the anterior communicating artery after surgery and embolization, occluded by placement of a Leo+baby intracranial stent. A case report. Neuroradiol J. 2013;26:320-6.

6. Cagnazzo F, Limbucci N, Nappini S, Renieri L, Rosi A, Laiso A, Tiziano di Carlo D, Perrini P, Mangiafico S. Y-Stent-assisted coiling of wide-neck bifurcation Intracranial aneurysms: a meta-analysis. AJNR Am J Neuroradiol. 2019;40:122-8.

7. Cohen JE, Melamed I, Itshayek E. X-microstenting and transmesh coiling in the management of wide-necked tent-like anterior communicating artery aneurysms. J Clin Neurosci. 2014;21:664-7.

8. Cohen JE, Moscovici S, El Hassan HA, Doron O, Itshayek E. $\mathrm{T}$-microstent-assisted coiling in the management of ruptured widenecked anterior communicating artery aneurysms: choosing between Y, X and T. J Clin Neurosci. 2016;34:283-7.

9. Richter G, Engelhorn T, Struffert T, Doelken M, Ganslandt O, Hornegger J, Kalender WA, Doerfler A. Flat panel detector angiographic CT for stent-assisted coil embolization of broad-based cerebral aneurysms. AJNR Am J Neuroradiol. 2007;28:1902-8.

10. Struffert T, Saake M, Ott S, Engelhorn T, Gölitz P, Kloska S, Doelken M, Doerfler A. Intravenous flat detector CT angiography for non-invasive visualisation of intracranial flow diverter: technical feasibility. Eur Radiol. 2011;21:1797-801.

11. Mascitelli JR, Moyle H, Oermann EK, Polykarpou MF, Patel AA, Doshi AH, Gologorsky Y, Bederson JB, Patel AB. An update to the Raymond-Roy occlusion classification of intracranial aneurysms treated with coil embolization. J Neurointerv Surg. 2015;7:496-502.

12. Chalouhi N, Starke RM, Koltz MT, Jabbour PM, Tjoumakaris SI, Dumont AS, Rosenwasser RH, Singhal S, Gonzalez LF. Stent-assisted coiling versus balloon remodeling of wideneck aneurysms: comparison of angiographic outcomes. AJNR Am J Neuroradiol. 2013;34:1987-92.

13. Shapiro M, Babb J, Becske T, Nelson PK. Safety and efficacy of adjunctive balloon remodeling during endovascular treatment of intracranial aneurysms: a literature review. AJNR Am J Neuroradiol. 2008;29:1777-81.
14. Song J, Shin YS. Antiplatelet drug resistance did not increase the thromboembolic events after stent-assisted coiling of unruptured intracranial aneurysm: a single center experience of 99 cases. Neurol Sci. 2017;38:879-85.

15. Möhlenbruch MA, Herweh C, Jestaedt L, Stampfl S, Schönenberger S, Ringleb PA, Bendszus M, Pham M. The FRED flowdiverter stent for intracranial aneurysms: clinical study to assess safety and efficacy. AJNR Am J Neuroradiol. 2015;36:1155-61.

16. Luecking H, Engelhorn T, Lang S, Goelitz P, Kloska S, Roessler K, Doerfler A. FRED flow diverter: a study on safety and efficacy in a consecutive group of 50 patients. AJNR Am J Neuroradiol. 2017;38:596-602.

17. Killer-Oberpfalzer M, Kocer N, Griessenauer CJ, Janssen H, Engelhorn T, Holtmannspötter M, Buhk JH, Finkenzeller T, Fesl G, Trenkler J, Reith W, Berlis A, Hausegger K, Augustin M, Islak C, Minnich B, Möhlenbruch M. European multicenter study for the evaluation of a dual-layer flow-diverting stent for treatment of wideneck Intracranial aneurysms: the European flow-redirection Intraluminal device study. AJNR Am J Neuroradiol. 2018;39:841-7.

18. Becske T, Brinjikji W, Potts MB, Kallmes DF, Shapiro M, Moran CJ, Levy EI, McDougall CG, Szikora I, Lanzino G, Woo HH, Lopes DK, Siddiqui AH, Albuquerque FC, Fiorella DJ, Saatci I, Cekirge SH, Berez AL, Cher DJ, Berentei Z, Marosfoi M, Nelson PK. Longterm clinical and angiographic outcomes following pipeline embolization device treatment of complex internal carotid artery aneurysms: five-year results of the pipeline for Uncoilable or failed aneurysms trial. Neurosurgery. 2017;80:40-8.

19. Koch MJ, Stapleton CJ, Raymond SB, Williams S, LeslieMazwi TM, Rabinov JD, Patel AB. LVIS Blue as a low porosity stent and coil adjuvant. J Neurointerv Surg. 2018;10:682-6.

20. Lieber BB, Sadasivan C. Endoluminal scaffolds for vascular reconstruction and exclusion of aneurysms from the cerebral circulation. Stroke. 2010;41(10 Suppl):S21-5.

21. Hong B, Wang K, Huang Q, Xu Y, Fang X, Li Z, Liu J. Effects of metal coverage rate of flow diversion device on neointimal growth at side branch ostium and stented artery: an animal experiment in rabbit abdominal aorta. Neuroradiology. 2012;54:849-55.

22. Machi P, Costalat V, Lobotesis K, Ruiz C, Cheikh YB, Eker O, Gascou G, Danière F, Riquelme $\mathrm{C}$, Bonafé $\mathrm{A}$. LEO baby Stent use following balloon-assisted coiling: single- and dual-stent technique-immediate and midterm results of 29 consecutive patients. AJNR Am J Neuroradiol. 2015;36:2096-103.

23. Pumar JM, Arias-Rivas S, Rodríguez-Yáñez M, Blanco $M$, Ageitos M, Vazquez-Herrero F, Castiñeira-Mourenza JA, Masso A. Using Leo plus stent as flow diverter and endoluminal remodeling in endovascular treatment of intracranial fusiform aneurysms. J Neurointerv Surg. 2013;5 Suppl 3:iii22-7.

24. Djurdjevic T, Young V, Corkill R, Briley D, Küker W. Treatment of broad-based intracranial aneurysms with low profile braided stents: a single center analysis of 101 patients. J Neurointerv Surg. 2019;11:591-7.

25. Aydin K, Arat A, Sencer S, Barburoglu M, Men S. Stent-assisted coiling of wide-neck intracranial aneurysms using low-profile LEO baby stents: initial and midterm results. AJNR Am J Neuroradiol. 2015;36:1934-41. 